\title{
ALTERAÇÕES FISIOLÓGICAS DURANTE A HIDRATAÇÃO DE SEMENTES DE Dalbergia nigra ((Vell.) Fr. All. ex Benth.)
}

\author{
PHYSIOLOGICAL CHANGES DURING HYDRATION OF Dalbergia nigra ((Vell.) \\ Fr. All. ex Benth.) SEEDS
}

\begin{abstract}
Glauciana da Mata Ataíde ${ }^{1}$ Eduardo Euclydes de Lima e Borges ${ }^{2}$
José Francisco de Carvalho Gonçalves ${ }^{3}$ Valéria Monteze Guimarães ${ }^{4}$ Andressa Vasconcelos Flores ${ }^{5}$
\end{abstract}

\section{RESUMO}

Durante a germinação, uma série de eventos sequenciais ocorre nas sementes em resposta a fatores endógenos e/ou exógenos às mesmas. O objetivo deste trabalho foi investigar as alterações fisiológicas decorrentes da hidratação controlada em água e da temperatura (fatores exógenos) em sementes de Dalbergia nigra (jacarandá-da-bahia). Para tanto, dois lotes de sementes, um de alto e um de baixo vigor foram utilizados nos ensaios. As sementes pertencentes aos dois lotes, após desinfestadas com Captan 0,5\%, foram então hidratadas em água, pelo método da atmosfera úmida (umidade relativa de 95-99\%), até atingirem quatro níveis de hidratação: $10,15,20$ ou $25 \%$ de teor de água nas sementes, nas temperaturas de 15 e $25^{\circ} \mathrm{C}$. Após os tratamentos foram analisadas as seguintes variáveis: curva de embebição, percentagem de germinação, índice de velocidade (IVG) e condutividade elétrica. Os resultados mostraram que não houve diferença significativa na resposta fisiológica das sementes entre as temperaturas. Por outro lado, para a hidratação verificou-se que até $15 \%$ do teor de água aumentou a qualidade fisiológica das sementes de ambos os lotes, que apresentaram maiores valores de germinação, IVG e menores quantidades de compostos lixiviados. A partir de $15 \%$ de teor de água verificou-se redução na qualidade das sementes classificadas como de alto vigor, enquanto aquelas de baixo vigor continuaram apresentando respostas positivas em 20 e $25 \%$ de teor de água. Diante disto, conclui-se que a técnica de hidratação controlada em água favorece a germinação de sementes de Dalbergia nigra, independentemente do vigor das mesmas. A hidratação no teor de água de $15 \%$ é a mais indicada para incrementar a qualidade das sementes. A hidratação nos valores abaixo ou acima resultaram em redução no estímulo.

Palavras-chave: embebição; germinação; vigor; jacarandá-da-bahia.

\begin{abstract}
During germination, a series of sequential events occur in seeds in response to endogenous and / or exogenous factors. The objective of this study was to investigate the physiological changes resulting from the controlled hydration in water and temperature in seeds of jacaranda-da-bahia (Dalbergia nigra). To this end, two lots of seeds separated as high and low vigor were used in the tests. Seeds belonging to the two lots, after desinfect, were hydrated in water, with the method of humid atmosphere (relative humidity

1 Engenheira Florestal, Dra., Professora do Instituto de Florestas, Universidade Federal Rural do Rio de Janeiro, Rod. BR 465, Km 07, CEP 23895-000, Seropédica (RJ), Brasil. glaucianadamata@yahoo.com.br

2 Engenheiro Florestal, Dr., Professor do Departamento de Engenharia Florestal, Universidade Federal de Viçosa, Av. Peter Henry Rolfs, s/n, Campus Universitário, CEP 36570-000, Viçosa (MG), Brasil. elborges@ufv.br

3 Engenheiro Agrônomo, Dr., Professor do Instituto Nacional de Pesquisas da Amazônia, Av. André Araújo, 2936, Petrópolis, CEP 69011-970, Manaus (AM), Brasil. jfc@inpa.gov.br

4 Farmacêutica Bioquímica, Dra., Professora do Departamento de Bioquímica e Biologia Molecular, Universidade Federal de Viçosa, Av. Peter Henry Rolfs, s/n, Campus Universitário, CEP 36570-000, Viçosa (MG), Brasil. vmonteze@ufv.br

5 Engenheira Florestal, Dra., Professora do Departamento de Engenharia Florestal, Universidade Federal de Santa Catarina, Rod. Municipal Ulisses Gaboardi, Km 3, Fazenda Pessegueirinho, CEP 89520-000, Curitibanos (SC), Brasil. andressafloressm@yahoo.com.br
\end{abstract}


95-99\%) to reach four hydration levels: $10,15,20$ and 25\% moisture content in seeds, in temperatures (exogenous factor) of 15 and $25^{\circ} \mathrm{C}$. After hydration and temperature treatments, were analyzed the following variables: curve soaking, germination percentage, germination speed index (GSI) and electrical conductivity. The results showed no significant difference in seeds physiological response between the temperatures. On the other hand, for hydration was found that up to $15 \%$ moisture content increased the seeds physiological quality of both lots, which showed higher germination values, IVG and smaller amounts of leached compounds. From 15\% moisture content were found a reduction in the quality of seeds classified as high vigor, while those of low vigor continued to show positive responses in 20 and $25 \%$ humidity. Given this, it is concluded that the technique of controlled hydration in water favors the germination of Dalbergia nigra seeds, independent of the vigor. Hydration moisture content of $15 \%$ is more appropriate to increase the seeds quality. The hydration in values below or above resulted in a decrease in the stimulus.

Keywords: imbibitions; germination; force; Dalbergia nigra.

\section{INTRODUÇÃO}

No decorrer do processo germinativo, eventos sucessivos ocorrem para consolidar o crescimento do embrião e a emissão das estruturas que darão condições para o estabelecimento da nova planta, destacando-se a ativação da respiração (BEWLEY; BLACK, 1994), o reparo de macromoléculas (OSBORNE, 1993), a mobilização de reservas (GALLARDO et al., 2001) e o reinício do ciclo celular (CASTRO et al, 1995; VÁSQUEZRAMOS; SÁNCHEZ, 2004). Quase todos esses mecanismos associados ao início e adequado funcionamento da germinação estão relacionados ao teor de água nas células e tecidos da semente.

Assim, para que uma semente complete a germinação, é necessário que alcance o teor de água suficiente para que ocorra a ativação das reações químicas relacionadas ao metabolismo, com consequente expansão radicular. Nesse sentido, tratamentos pré-germinativos que utilizam meios com restrição hídrica ou embebição controlada das sementes em água têm sido usados, visando aumentar a uniformidade e a velocidade da germinação (SCHWEMBER; BRADFORD, 2010).

Tais tratamentos envolvem determinado período de hidratação controlada até um ponto próximo da emergência da plântula (POWELL et al., 2000). A semente absorve água até o nível em que todos os processos preparatórios ocorrem, sem, contudo, atingir a fase de alongamento celular e, consequentemente, a protrusão da raiz primária (VARIER; VARI; DADLANI, 2010; MURUNGU, 2011), assim como, sem que ocorra a embebição muito rápida, o que poderia causar danos às membranas celulares (CASTRO; HILHORST, 2004).
Dentre os métodos empregados, são encontrados na literatura trabalhos avaliando o condicionamento das sementes em soluções de Polietilenoglicol (PEG) (KISSMANN et al., 2010; LIMA; MARCOS FILHO, 2010; MARTINS; PEREIRA; MARCHI, 2011), manitol (COSTA et al., 2004; ÁVILA et al., 2007) ou a hidratação das sementes em água, utilizando metodologias de substrato umedecido e atmosfera úmida (ARAÚJO; ROSSETTO, 2005; AMOOAGHAIE, 2011).

A hidratação em água apresenta-se como um método simples e barato para propiciar aumento da porcentagem, velocidade e sincronização da germinação, e favorecer o desenvolvimento das plântulas (FUJIKURA et al., 1993; PINEDO; FERRAZ, 2008). Estes aspectos foram destacados em experimentos com o condicionamento em água das espécies Anadenanthera peregrina, Parkia multijuga e Astrocaryum aculeata (FERREIRA; GENTIL, 2006; CALVI et al., 2008; PINEDO; FERRAZ, 2008).

Dalbergia nigra, popularmente conhecida como jacarandá-da-bahia, é uma espécie classificada como secundária tardia a clímax e apresenta distribuição natural restrita à Floresta Atlântica, mais especificamente do sul da Bahia até o norte de São Paulo (LORENZI, 1992). Além de apresentar alto potencial para o manejo florestal sustentável, sua madeira pode ser utilizada na fabricação de mobiliário de luxo e de instrumentos musicais, como o piano (RÊGO; POSSAMAI, 2003; CARVALHO, 1994). Quanto às propriedades tecnológicas, Dalbergia nigra possui alta durabilidade natural, tem sido usada como decorativa, além de apresentar madeira dura e moderadamente pesada, fato que implica maior valor agregado (RIZZINI, 1972). Tal valorização contribui para exploração inadequada, e 
a consequente inclusão na lista oficial das espécies da flora brasileira ameaçadas de extinção, na categoria vulnerável (IBAMA, 2008).

Portanto, pesquisas relacionadas ao processo germinativo das sementes de Dalbergia nigra, podem servir de base para eventual plano de manejo e uso desta importante espécie do bioma Mata Atlântica. Diante destes precedentes, com a execução deste trabalho a expectativa é que se possam entender melhor os efeitos da hidratação controlada e da temperatura sobre lotes de alto e baixo vigor de Dalbergia nigra, a partir das mudanças fisiológicas ocorridas durante a germinação.

\section{MATERIAIS E MÉTODOS}

As sementes de Dalbergia nigra utilizadas nesta pesquisa foram coletadas diretamente de duas árvores-matrizes na região de Viçosa, Minas Gerais, em setembro de 2010. Aparentemente, os frutos das matrizes estavam no mesmo período de maturação e após beneficiados, foram eliminadas as sementes atacadas por pragas e doenças, deterioradas ou danificadas e então acondicionadas em tambores de fibra e armazenadas em câmera fria a $5^{\circ} \mathrm{C}$ e $60 \%$ UR até a realização dos experimentos.

As sementes selecionadas de cada matriz constituíram os lotes I e II, os quais foram, inicialmente, caracterizados quanto ao teor de umidade, dados biométricos (comprimento, largura e espessura das sementes), massa de mil sementes, porcentagem de germinação, índice de velocidade de germinação (IVG) e condutividade elétrica.

As sementes destes lotes foram imersas em fungicida Captan 0,5\% por três minutos e em seguida colocadas para hidratar em água até atingirem aproximadamente quatro níveis de hidratação: $10,15,20$ e $25 \%$ de umidade nas sementes. Para ajustar o teor de água para as quantidades desejadas, utilizou-se o método de hidrocondicionamento em atmosfera úmida, sendo as sementes mantidas em sacos de náilon tipo filó $(10 \times 13 \mathrm{~cm})$ em dessecadores saturados (95-99\% UR), nas temperaturas de $15 \mathrm{e}$ $25^{\circ} \mathrm{C}$. A marcha de absorção de água foi conduzida por meio de pesagens constantes das amostras, até que atingissem a umidade proposta, segundo procedimento descrito por Caseiro et al. (2004). O tempo de embebição até as amostras de sementes adquirirem o nível de hidratação desejado foi calculado pelo teor de água inicial e massa de cada uma das amostras, conforme a expressão abaixo (CROMARTY; ELLIS; ROBERTS, 1990):

$$
M=\frac{\left(100-\mathrm{CA}_{1}\right) \times \mathrm{Mi}}{\left(100-\mathrm{CA}_{2}\right)}
$$

Em que: $\mathrm{M}=$ massa no conteúdo de água desejada (g); $\mathrm{Mi}=$ massa no conteúdo de água original $(\mathrm{g})$; $\mathrm{CA}_{1}=$ conteúdo de água original (\% base úmida); $\mathrm{CA}_{2}=$ conteúdo de água desejado (\% base úmida).

Após chegarem às umidades predefinidas, as sementes foram utilizadas para os testes fisiológicos:

\section{Teor de água}

Determinado pelo método da estufa a $105 \pm 3^{\circ} \mathrm{C}$ por 24 horas, utilizando-se três repetições de 20 sementes para cada tratamento, com resultados expressos em porcentagem (base úmida) (BRASIL, 2009).

\section{Germinação}

As sementes foram tratadas com o fungicida Captan $0,5 \%$ por três minutos e colocadas para germinar em placas de Petri com $9 \mathrm{~cm}$ de diâmetro, forradas duplamente com papel de filtro do tipo germitest umedecido com $4 \mathrm{~mL}$ de água destilada. As placas foram mantidas em germinador a $25^{\circ} \mathrm{C}$ e sob luz constante, proporcionada por quatro lâmpadas $40 \mathrm{~W}$ tipo luz do dia, durante 12 dias. A porcentagem de germinação foi determinada pela contagem diária das sementes com observação da emissão da radícula a partir do critério botânico, sendo os resultados expressos em porcentagem média. Foram utilizadas cinco repetições de 20 sementes por tratamento.

\section{Índice de velocidade de germinação}

Para o cálculo do índice de velocidade de germinação (IVG), foi utilizada a fórmula proposta por Maguire (1962): IVG $=\sum\left(\frac{n_{t}}{t_{i}}\right)$, em que, $n_{i}$ é o número de sementes por dia e $\mathrm{t}_{\mathrm{i}}$ é o tempo (dias).

\section{Condutividade elétrica}

Com a finalidade de comparar a integridade das membranas após a aplicação dos tratamentos, foi conduzido o teste de condutividade elétrica, pelo método de massa. Quatro repetições de 50 sementes foram pesadas em balança digital com precisão de 
duas casas decimais e, em seguida, colocadas em erlenmeyer com $75 \mathrm{~mL}$ de água deionizada a $25^{\circ} \mathrm{C}$ por 36 horas (MARQUES; PAULA; RODRIGUES, 2002a). A condutividade elétrica dos lixiviados foi determinada utilizando-se condutivímetro MICRONAL, modelo B 330, eletrodo com constante igual a 1,0 . O resultado foi expresso em $\mu \mathrm{s} . \mathrm{cm}^{-1} \cdot \mathrm{g}^{-1}$ de semente.

\section{Delineamento experimental e análises estatísticas}

O delineamento experimental utilizado foi o inteiramente casualizado (DIC), obedecendo a experimento fatorial $4 \times 2$ dentro de cada lote (quatro teores de umidade e duas temperaturas), com a testemunha (sementes sem hidratação) como tratamento adicional. Os resultados foram submetidos à análise de variância (ANOVA) e a comparação entre os diferentes tratamentos feita pelo teste de Tukey a 5\% de significância.

\section{RESULTADOS E DISCUSSÃO}

As sementes pertencentes ao lote I possuíam menor teor inicial de água e apresentaram-se maiores, com médias de comprimento, largura e espessura superiores ao lote II (Tabela 1). Estas sementes exibiram ainda maior massa, correspondendo a cerca de 15.840 sementes por quilograma, enquanto o lote II possuía aproximadamente 21.687 sementes. O valor encontrado para o lote I foi semelhante ao peso de mil sementes de Dalbergia nigra apresentado por Davide, Faria e Botelho (1995), de 17.300 sementes, ao passo que o lote II correspondeu aos valores encontrados por Marques; Paula e Rodrigues (2002b), de 20.004, 20.032 e 19.402 sementes, para três lotes distintos da espécie.

O tamanho e o peso das sementes são características relacionadas ao processodematuração fisiológica, onde se associam ao desenvolvimento de fitormônios durante a maturação e desenvolvimento da semente (LABOURIAU, 1983) e às diferenças no número e tamanho das células presentes no embrião, endosperma e tegumento (OHTO et al., 2009). Estas características podem variar entre espécies e dentro da mesma espécie, dependendo das condições do local e da árvore-matriz em que foram coletadas, visto que estão sob forte controle genético, principalmente, de origem materna (BAGCHI; JOSHI; RAWAT, 1989). Neste sentido, os valores encontrados para a espécie no presente trabalho, comparados aos de outros autores, mostram que o comportamento que as sementes apresentam é uniforme, independentemente do local de origem, sendo possível supor que o efeito genético perde importância, ficando o grau de maturação como o elemento determinante da qualidade das sementes.

A porcentagem de germinação e a condutividade elétrica dos dois lotes foram estatisticamente diferentes, com o lote I apresentando valores superiores de germinação e menor valor de condutividade em relação ao lote II. O teste de vigor também mostrou o lote I como superior, com maiores médias de IVG (Tabela 2). Dessa forma, as três características avaliadas discriminaram o lote I como de alto vigor e o lote II como de baixo vigor.

Como o lote I possuía sementes de tamanho e densidade superiores, estas características também podem ter exercido influência no processo de germinação, haja vista que as sementes maiores são as que foram melhor nutridas durante seu desenvolvimento e que normalmente possuem embriões bem formados e com maiores quantidades de reservas sendo, potencialmente, as mais vigorosas (CARVALHO; NAKAGAWA, 2000; GASPAR; NAKAGAWA, 2002).

A aplicação do teste de germinação juntamente a testes de vigor em diferentes lotes permite a avaliação mais adequada da qualidade dessas sementes (LARRÉ; MORAES; LOPES, 2009). As comparações de vigor de sementes entre matrizes, progênies e procedências também

TABELA 1: Caracterização dos lotes de sementes I e II de Dalbergia nigra quanto ao teor inicial de água (U), dados biométricos (comprimento, largura e espessura) e à massa de mil sementes (MMS).

TABLE 1: Characterization of Dalbergia nigra seed lots I and II on the initial moisture content (U), biometric data (length, width and thickness) and one thousand seeds weigh (MMS).

\begin{tabular}{cccccc}
\hline & $\mathrm{U}(\%)$ & Comprimento $(\mathrm{mm})^{1}$ & ${\text { Largura }(\mathrm{mm})^{1}}^{1}$ & Espessura $(\mathrm{mm})^{1}$ & MMS (g) \\
\cline { 2 - 6 } Lote I & 7,92 & $10,4 \pm 0,5$ & $5,5 \pm 0,4$ & $1,5 \pm 0,2$ & 63,1 \\
Lote II & 8,98 & $9,3 \pm 0,5$ & $4,8 \pm 0,3$ & $1,4 \pm 0,2$ & 46,1 \\
\hline
\end{tabular}

Em que: ${ }^{1}$ Média \pm desvio padrão 
fornecem ao pesquisador dados adicionais na fase inicial de um programa de melhoramento ou conservação genética (SANTOS; PAULA, 2007). Sementes de mesmo genótipo podem apresentar aspectos fisiológicos distintos, de forma que a região e a área de produção e as condições climáticas durante a maturação afetam diretamente o desempenho das sementes maduras (MARCOS FILHO, 2005). Dessa forma, lotes de sementes da mesma espécie e idade cronológica podem exibir comportamento variável durante a germinação, ou mesmo quando armazenados sob mesmas condições (MAEDA et al., 1986; RABOTEAUX; ANDERSON, 2009).

TABELA 2: Caracterização dos lotes I e II de sementes de Dalbergia nigra quanto à porcentagem de germinação $(G)$, índice de velocidade de germinação (IVG) e condutividade elétrica (CE).

TABLE 2: Characterization of Dalbergia nigra seeds lots I and II on the germination percentage $(\mathrm{G})$, germination speed index (IVG) and electrical conductivity (CE).

\begin{tabular}{lccc}
\hline & $\mathrm{G}(\%)$ & IVG & $\mathrm{CE}\left(\mu \mathrm{s} . \mathrm{cm}^{-1} \mathrm{~g}^{-1}\right)$ \\
\hline Lote I & $80 \mathrm{a}$ & $1,85 \mathrm{a}$ & $112,7 \mathrm{a}$ \\
Lote II & $33 \mathrm{~b}$ & $0,74 \mathrm{~b}$ & $132,5 \mathrm{~b}$ \\
Valor de F & 34,5 & 36,7 & 12,6 \\
$\mathrm{CV}(\%)$ & 21,1 & 21,0 & 5,3 \\
\hline
\end{tabular}

Em que: Médias seguidas pela mesma letra, na coluna, não diferem entre si pelo teste de Tukey, a 5\%.

Sementes dos dois lotes exibiram curva característica de absorção de água (Figura 1). As sementes do lote II necessitaram de menor período de embebição para atingirem os graus de umidade desejados. Tal fato pode ser justificado pelo teor de água inicial superior neste lote em relação ao lote I. Isso também pode ter ocorrido devido às sementes do lote II serem de baixo vigor, como também foi observado em estudos de hidratação de sementes de Glycine max, nos quais se verificou que as mais deterioradas absorveram água mais rapidamente, visto que nestas as membranas celulares são mais permeáveis à entrada de água (BECKERT; SILVA, 2002). Por outro lado, é possível que a redução na permeabilidade das membranas libere parcialmente os solutos celulares para o meio, ficando parte destes nas sementes, próximos ao tegumento, conforme observado em sementes deterioradas de
Dalbergia nigra, em que se verificou redução do potencial hídrico, resultando na maior e mais rápida hidratação (BORGES; BORGES; BUCKERIDGE, 2000). Nas sementes mais vigorosas, o caminho da água torna-se mais complexo, mesmo tendo as aquaporinas (canais proteicos nas membranas) facilitando o fluxo através das células (MAUREL et al., 2008), além do potencial de parede que reduz a quantidade final de água nas células intactas (BRADFORD, 1990).

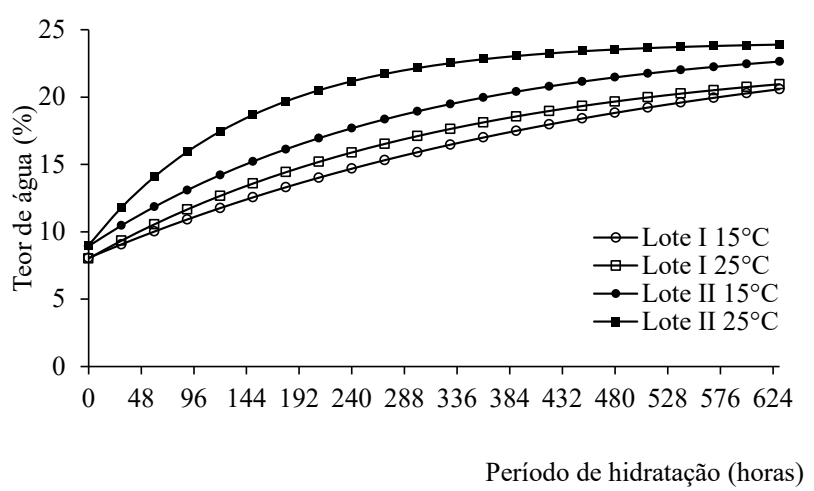

FIGURA 1: Absorção de água das sementes de Dalbergia nigra dos lotes I e II, nas temperaturas de 15 e $25^{\circ} \mathrm{C}$.

FIGURE 1: Water absorption of Dalbergia nigra seeds lots I and II, in the temperatures of 15 and $25^{\circ} \mathrm{C}$.

Em ambos os lotes, a temperatura de $25^{\circ} \mathrm{C}$ foi a que proporcionou maiores taxas de embebição. Em temperaturas mais altas ocorre diminuição na viscosidade da água (WOODSTOCK, 1988), de forma que a capacidade de absorção de água aumenta com o aumento da temperatura, sendo esta absorvida mais rapidamente pelos tecidos (KHAZAEI; MOHAMMADI, 2009). Percebe-se que esta explicação é clara para o lote I, não sendo, entretanto, para o lote II, no qual as curvas de embebição estão mais próximas.

$\mathrm{O}$ intervalo entre 20 e $30^{\circ} \mathrm{C}$ foi definido como o ótimo para a germinação de sementes de Dalbergia nigra (FERRAZ-GRANDE; TAKAKI, 2001). Dessa forma, apesar da embebição ser um processo físico-biológico, governado por reações de superfície entre a água e a matéria adsorvedora e, pela afinidade da semente em embeber em função da presença de substâncias osmoticamente ativas (PAZDERA; HOSNEDL, 2002), as condições adequadas de temperatura podem favorecer o rápido desenvolvimento das fases I e II do processo de germinação, iniciando-se a sucessão de eventos pela 
absorção de água (BILIGETU; SCHELLENBERG; MCLEOD, 2011).

As diferenças entre os teores de água desejados e obtidos não ultrapassaram 1,6 pontos percentuais (Tabela 3), sendo considerados satisfatórios para o desenvolvimento das etapas posteriores. Da mesma forma, o método da atmosfera úmida foi utilizado para a reidratação das sementes de Parkia multijuga com relativo sucesso, alcançando as umidades desejadas para efeito de tratamento com precisão adequada (RAMOS et al., 2000).

TABELA 3: Teores de água desejados e alcançados durante a hidratação dos lotes I e II de sementes de Dalbergia nigra, utilizando-se o método de atmosfera úmida, nas temperaturas de 15 e $25^{\circ} \mathrm{C}$.

TABLE 3: Moisture content desired and achieved during hydration of Dalbergia nigra seeds lots I and II, using the method of humid atmosphere at temperatures of 15 and $25^{\circ} \mathrm{C}$.

\begin{tabular}{ccccc}
\hline \multirow{2}{*}{$\begin{array}{c}\text { Temp. } \\
\left({ }^{\circ} \mathrm{C}\right)\end{array}$} & $\begin{array}{c}\text { Teor } \\
\text { desejado } \\
(\%)\end{array}$ & $\begin{array}{c}\text { Teor } \\
\text { alcançado } \\
(\%)\end{array}$ & $\begin{array}{c}\text { Teor } \\
\text { desejado } \\
(\%)\end{array}$ & $\begin{array}{c}\text { Teor } \\
\text { alcançado } \\
(\%)\end{array}$ \\
\hline \multirow{4}{*}{15} & 10 & 11,17 & 10 & 9,32 \\
& 15 & 15,66 & 15 & 15,19 \\
& 20 & 19,37 & 20 & 21,19 \\
& 25 & 25,81 & 25 & 25,12 \\
& 10 & 11,6 & 10 & 10,82 \\
& 15 & 14,66 & 15 & 15,94 \\
& 20 & 19,99 & 20 & 19,54 \\
& 25 & 26,12 & 25 & 25,91 \\
\hline
\end{tabular}

A umidade inicial das sementes é importante no processo germinativo, pois a retomada do metabolismo durante a germinação é iniciada mais rapidamente quanto mais rápido a semente alcançar o nível crítico de hidratação. $\mathrm{O}$ período de tempo necessário para que a hidratação ocorra varia conforme as características da espécie e da temperatura sob a qual as sementes se encontram. Assim, a água atua como o principal agente estimulador e controlador, proporcionando, mediante reações químicas, o enfraquecimento do tegumento, acréscimo no volume do embrião e dos tecidos de reserva, assim como aumento nos estímulos à digestão, translocação e assimilação de nutrientes, com consequente crescimento do eixo embrionário (MARCOS FILHO, 2005; GUIMARÃES; DIAS; LOUREIRO, 2008).

Os resultados da porcentagem de germinação das sementes, após atingirem os diferentes teores de água nas temperaturas de 15 e $25^{\circ} \mathrm{C}$, demonstraram que no nível de hidratação de $15 \%$ de umidade ocorreram os maiores valores de germinação para os dois lotes, independentemente da temperatura de embebição, que não foi significativa para os percentuais de germinação (Figura 2).

Entre os diferentes níveis de umidade, constata-se que para o lote I apenas a umidade de $25 \%$, a $25^{\circ} \mathrm{C}$, diferiu estatisticamente da testemunha, que já apresentava $80 \%$ germinação. No lote II, que possuía germinação inicial de $33 \%$, as sementes com umidade de 15,20 e $25 \%$ apresentaram médias superiores à testemunha e ao tratamento com hidratação de $10 \%$ em ambas as temperaturas. Neste lote, em sementes com $15 \%$ de umidade, os ganhos percentuais de 45 e $49 \%$ de germinação em relação à testemunha para as temperaturas 15 e $25^{\circ} \mathrm{C}$, respectivamente, indicam que a aplicação da hidratação em água foi eficiente para o aumento na porcentagem de germinação das sementes com menor qualidade fisiológica.

Possivelmente, as sementes de maior vigor encontram-se em estágio no qual a água adicional resultará em germinação, desde que mantidas as condições requeridas para tal. Entretanto, a absorção de água após determinado nível que permite que o metabolismo ocorra sem, contudo, permitindo que haja protrusão da radícula, resultará em deterioração das sementes (POWELL et al., 2000). Quando uma semente de menor vigor é submetida ao condicionamento, esta possui mais tempo para reparar as lesões metabólicas antes que ocorra a germinação, evitando assim maior deterioração (VARIER; VARI; DADLANI, 2010). O melhor desempenho germinativo das sementes de menor vigor tem sido relacionado ao desencadeamento dos mecanismos de reparo das membranas pela hidratação e à formação antecipada de metabólitos necessários à germinação (BURGASSER; POWELL, 1984; SUNG; CHANG, 1993). Por isso as sementes de baixo vigor tiveram aumentos de germinação, mesmo nas maiores temperaturas e maiores umidades que o lote I.

Estudos com outras espécies também observaram aumento na germinação com o condicionamento, como, por exemplo, em estudos 
(A)

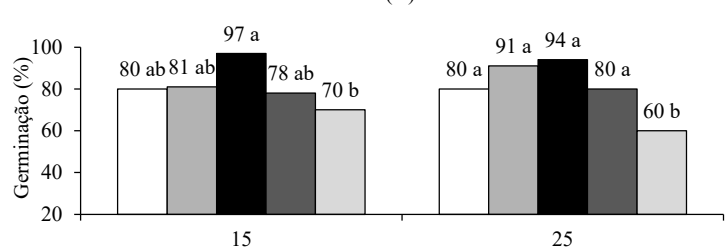

(B)

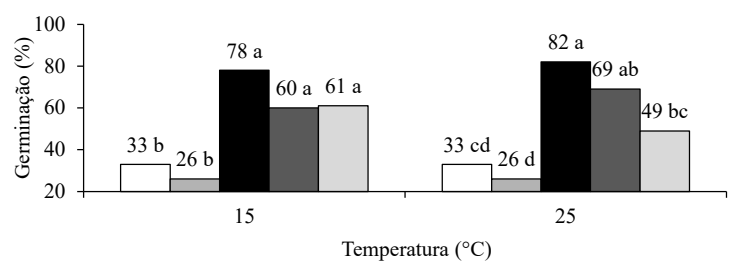

FIGURA 2: Germinação (\%) de sementes de Dalbergia nigra a partir dos teores iniciais de umidade de $10,15,20$ e $25 \%$, hidratadas nas temperaturas de 15 e $25^{\circ} \mathrm{C}$. A) Lote I; B) Lote II. Médias seguidas de mesma letra, dentro de cada lote e temperatura avaliados, não diferem entre si, a $5 \%$, pelo teste Tukey.

FIGURE 2: Germination (\%) of Dalbergia nigra seeds from the initial moisture contents of $10,15,20$ and $25 \%$ hydrated in temperatures of 15 and $25^{\circ} \mathrm{C}$. A) Lot I, B) Lot II. Means followed by same letter within each lot and measured temperature do not differ at $5 \%$, by Tukey's test.

de embebição de sementes de baixo vigor de tucumã (Astrocaryum aculeatum) foram observados ganhos significativos na germinação, que aumentaram de 58 para $70 \%$ quando as sementes passaram de 20 para $31 \%$ de umidade, momento a partir do qual a germinação decresceu (FERREIRA; GENTIL, 2006). A porcentagem de germinação foi aumentada significativamente após o condicionamento em água em sementes de Tanacetum cinerariifolium (LI et al., 2011) e Cucurbita maxima (SUN et al., 2011). Dicionário

Por outro lado, a hidratação em sementes de Anadenanthera peregrina, que já apresentavam germinação de $86 \%$ na testemunha, não provocou acréscimos significativos na porcentagem de germinação, que teve valor de $87 \%$ após a aplicação do tratamento (REIS; CUNHA, 1997).
Os maiores valores de índices de velocidade de germinação foram observados nas sementes com grau de umidade de 15\%, em ambos os lotes (Figura 3). Também não foram verificadas diferenças significativas entre as temperaturas testadas para o IVG, assim como para o percentual de germinação. Para o lote $\mathrm{I}$, todos os níveis de hidratação apresentaram valores de IVG maiores que a testemunha, enquanto no lote II os valores para a testemunha e com $10 \%$ de umidade foram iguais estatisticamente, que, por sua vez, foram inferiores e diferiram dos demais valores de umidade nas sementes.

(A) $\quad$ Test. $\square 10 \% \quad \square 15 \% \quad \square 20 \% \quad \square 25 \%$

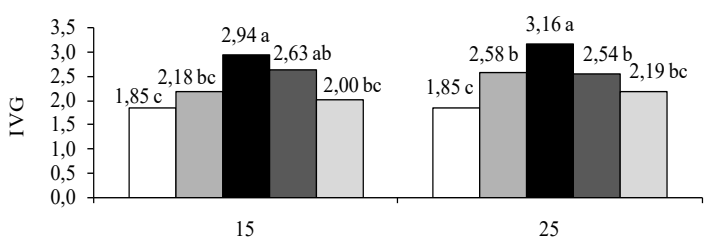

(B)

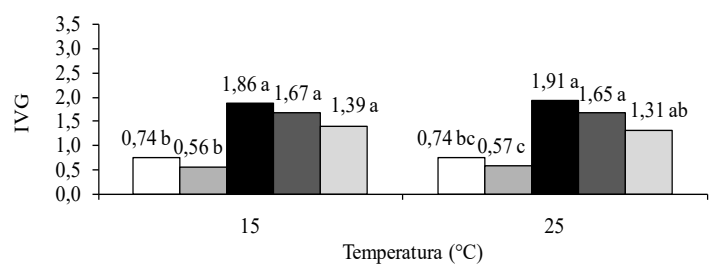

FIGURA 3: Índice de velocidade de germinação (IVG) de sementes de Dalbergia nigra a partir dos teores iniciais de umidade de $10,15,20$ e $25 \%$, hidratadas nas temperaturas de 15 e $25^{\circ} \mathrm{C}$. A) Lote $\mathrm{I}$; B) Lote II. Médias seguidas de mesma letra, dentro de cada lote e temperatura avaliados, não diferem entre si, a $5 \%$, pelo teste Tukey.

FIGURE 3: Germination speed index (IVG) of Dalbergia nigra seeds from the initial moisture contents of 10,15, 20 and $25 \%$ hydrated in temperatures of 15 and $25^{\circ} \mathrm{C}$. A) Lot I, B) Lot II. Means followed by same letter within each lot and measured temperature do not differ at $5 \%$, by Tukey's test.

Para as sementes que já passaram anteriormente por um processo de embebição, quando colocadas novamente em contato com a água, não é necessária a reiteração dos processos já ocorridos na primeira hidratação e 
que possibilitaram a reorganização e ativação de processos celulares que estavam inativos devido ao processo de dessecação (BEWLEY; BLACK, 1994). Dessa forma, as sementes hidratadas estão fisiologicamente mais próximas ao início da fase III de embebição e, consequentemente, da protrusão da radícula, apresentando maiores valores de velocidade de germinação. Entretanto, percebe-se que, embora os teores de água fossem semelhantes entre os dois lotes de sementes de jacarandá, não foi o nível de hidratação o determinante da maior velocidade de germinação, mas o vigor do lote. Tecnicamente, a duração adequada do período de condicionamento em água apresenta-se como fator fundamental para o vigor das sementes, pois ao melhorar a germinação, pôde assegurar o estabelecimento da plântula em condições de campo e fornecer parâmetros para a aplicação dos tratamentos pré-germinativos (GHASSEMIGOLEZANI et al., 2010). É nítido o efeito do período adequado de hidratação em ambos os lotes, quando se percebe que o menor teor de água resulta em menor resposta à germinação, provavelmente por não estar o nível de hidratação próximo do início da fase III. Por outro lado, o excesso causa redução no vigor, independentemente da qualidade inicial dos lotes, provavelmente por algum efeito danoso ao metabolismo, visto com mais clareza nas sementes do lote II, no teor de água $25 \%$, a $25^{\circ} \mathrm{C}$. Pesquisas confirmam os efeitos positivos da embebição em água sobre o vigor e germinação das sementes em Malpighia punicifolia, Triplaris americana, Egletes viscosa e Sorghum bicolor (AZEREDO et al., 2005; MENDONÇA et al., 2005; BEZERRA et al., 2006;
MORADI; YOUNSEI, 2009).

Sementes de Dalbergia nigra submetidas à hidratação a temperatura de $15^{\circ} \mathrm{C}$, independentemente do grau de hidratação e do vigor no lote exibiram valores de condutividade inferiores às testemunhas, para os dois lotes (Tabela 4). Na temperatura de $25^{\circ} \mathrm{C}$, os níveis de hidratação 10,15 e $20 \%$ diferiram da testemunha para o lote I, enquanto no lote II foram observadas médias semelhantes entre a testemunha e os demais tratamentos.

$\mathrm{Na}$ embebição lenta, há tempo suficiente para que as membranas das células, compostas por uma camada dupla de fosfolipídios, que, ao se desidratarem, passam de um estado fluído para um estado de gel, voltem ao estado cristalino líquido, sem ocorrer danos celulares e, por conseguinte, efluxo de compostos carregados eletricamente ou íons que configurem a lixiviação (CASTRO; HILHORST, 2004). Por outro lado, a absorção de água pelas sementes dos lotes I e II até $25 \%$ de umidade na temperatura de $25^{\circ} \mathrm{C}$ causou alterações significativas na integridade das membranas, que apresentaram maiores quantidades de lixiviados em relação aos demais níveis de hidratação. A temperatura mais elevada, associada ao maior período de embebição e possível deterioração, pode ter provocado mudanças na conformação dos fosfolipídios presentes nas membranas, que resultaram em maiores valores de condutividade elétrica.

Em sementes de Peltophorum dubium após o precondicionamento em água durante 24 horas, as membranas apresentaram-se mais bem estruturadas, com menor concentração de eletrólitos

TABELA 4: Condutividade elétrica (CE) $\left(\mu \mathrm{s} . \mathrm{cm}^{-1} \cdot \mathrm{g}^{-1}\right)$ de sementes dos lotes I e II de Dalbergia nigra em diferentes teores de umidade $(10,15,20$ e $25 \%)$, hidratadas nas temperaturas de 15 e $25^{\circ} \mathrm{C}$.

TABLE 4: Electrical conductivity (CE) $\left(\mu \mathrm{s} . \mathrm{cm}^{-1} \cdot \mathrm{g}^{-1}\right)$ of Dalbergia nigra seed lots I and II at different moisture contents $(10,15,20$ and $25 \%)$, hydrated at temperatures of 15 and $25^{\circ} \mathrm{C}$.

\begin{tabular}{ccccc}
\hline \multirow{2}{*}{ Umidade (\%) } & \multicolumn{3}{c}{ Lote I } & \multicolumn{3}{c}{ Lote II } \\
\cline { 2 - 5 } & \multicolumn{4}{c}{ Temperatura $\left({ }^{\circ} \mathrm{C}\right)$} \\
\cline { 2 - 5 } & $112,704 \mathrm{~b}$ & $112,704 \mathrm{~b}$ & $132,524 \mathrm{c}$ & $132,524 \mathrm{ab}$ \\
Test. & $91,077 \mathrm{aA}$ & $87,657 \mathrm{aA}$ & $121,579 \mathrm{~b} \mathrm{~A}$ & $126,002 \mathrm{aA}$ \\
10 & $87,413 \mathrm{aA}$ & $88,674 \mathrm{aA}$ & $96,935 \mathrm{aA}$ & $111,758 \mathrm{aA}$ \\
15 & $89,270 \mathrm{aA}$ & $97,772 \mathrm{aA}$ & $126,114 \mathrm{~b} \mathrm{~A}$ & $130,508 \mathrm{aA}$ \\
20 & $88,606 \mathrm{aA}$ & $113,852 \mathrm{~b} \mathrm{~B}$ & $125,571 \mathrm{~b} \mathrm{~A}$ & $157,823 \mathrm{~b} \mathrm{~B}$ \\
25 & &
\end{tabular}

Em que: Médias seguidas de mesma letra minúscula nas colunas e maiúscula nas linhas, dentro de cada lote, não diferem entre si, a $5 \%$, pelo teste Tukey. 
liberados pelas sementes (PEREZ; NEGREIROS, 2001). A menor perda de vigor e viabilidade das sementes após a hidratação em água é associada à redução na lixiviação de açúcares, ao aumento da atividade de enzimas do sistema antioxidante e à menor peroxidação de lipídios nas sementes, resultando em diminuição no extravasamento celular (RUDRAPAL; NAKAMURA, 1998; ELLA; DIONISIO-SESE; ISMAIL, 2011).

\section{CONCLUSÕES}

Diante dos resultados obtidos conclui-se que a técnica de hidratação controlada em água favoreceu a germinação da espécie Dalbergia nigra, independentemente do vigor das sementes;

A manutenção das sementes em hidratação até $15 \%$ de umidade foi a mais indicada para o incremento na qualidade das sementes;

A hidratação por períodos em que as sementes alcancem $10 \%$ de umidade e por longos períodos, como até $25 \%$, foi menos benéfica, conferindo alterações fisiológicas que foram verificadas pela percentagem de germinação e pelo índice de velocidade de germinação.

\section{REFERÊNCIAS BIBLIOGRÁFICAS}

AMOOAGHAIE, R. The effect of hydro and osmopriming on alfalfa seed germination and antioxidant defenses under salt stress. African Journal of Biotechnology, Bowie, v. 10, n. 33, p. 6269-6275, 2011.

ARAÚJO, A. E. S.; ROSSETTO, C. A. V. Influência da hidratação controlada na germinação de sementes de amendoim armazenadas. Científica, São Paulo, v. 33, n. 2, p. 199-207, 2005.

ÁVILA, M. R. et al. Influência do estresse hídrico simulado com manitol na germinação de sementes e crescimento de plântulas de canola. Revista Brasileira de Sementes, Brasília, v. 29, n. 1, p. 98-106, 2007.

AZEREDO, G. A. et al. Viabilidade e vigor de sementes de acerola (Malpighia punicifolia) submetidas a embebição sob diferentes temperaturas. Pesquisa Agropecuária Tropical, Goiânia, v. 35, p. 81-84, 2005.

BAGCHI, S. K.; JOSHI, D. N.; RAWAT, D. S. Variation in seed size of Acacia spp. Silvae Genetica, Großhansdorf, v. 39, n. 3-4, p. 107-110, 1989.

BECKERT, O. P.; SILVA, W. R. O uso da hidratação para estimar o desempenho de sementes de soja.
Bragantia, Campinas, v. 61, n. 1, p. 61-69, 2002. BEWLEY, J. D.; BLACK, M. Seeds: physiology of development and germination. Nova York: Plenum Press, 1994.

BEZERRA, A. M. et al. Efeito da pré-embebição e aplicação de ácido giberélico na germinação de sementes de macela. Revista Brasileira de Sementes, Brasília, v. 28, n. 3, p. 185-190, 2006. BILIGETU, B.; SCHELLENBERG, M. P.; MCLEOD, J. G. The effect of temperature and water potential on seed germination of poly-cross side-oats grama (Bouteloua curtipendula (Michx.) Torr.) population of Canadian Prairie. Seed Science and Technology, Bassersdorf, v. 39, n. 1, p. 74-81, 2011.

BORGES, E. E. L.; BORGES, R. C. G.; BUCKERIDGE, M. S. Alterações nas composições de carboidratos e de ácidos graxos em sementes de Jacarandá-da-Bahia os mocondicionadas. Revista Brasileira de Fisiologia Vegetal, Campinas, v. 12, n. 1, p.10-16, 2000.

BRADFORD, K. J. A water relations analysis of seed germination rates. Plant Physiology, Rockville, v. 94, p. 840-849, 1990.

BRASIL. Ministério da Agricultura, Pecuária e Abastecimento. Regras para análise de sementes. Brasília: SDA/ACS, 2009. 399 p.

BURGASSER, R. W.; POWELL, A. A. Evidence for repair processes in the invigoration of seeds by hydration. Annals of Botany, Exeter, v. 53, p. 753-757, 1984.

CALVI, G. O. et al. Tratamentos de pré-embebição para aumento do desempenho da germinanção de sementes de Parkia multijuga Benth. Revista Forestal Latinoamericana, Mérida, v. 23, n. 2, p. 53-65, 2008.

CARVALHO, N. M.; NAKAGAWA, J. Sementes: ciência, tecnologia e produção. Campinas: Fundação Cargill, 2000. 424 p.

CARVALHO, P. E. R. Espécies florestais brasileiras: recomendações, silviculturas, potencialidades e uso da madeira. Colombo: Embrapa-CNPF; Brasília: Embrapa-SPI, 1994. $638 \mathrm{p}$.

CASTRO, R. D.; HILHORST, H. W. M. Embebição e reativação do metabolismo. In: FERREIRA, A. G.; BORGHETTI, F. (Eds.). Germinação: do básico ao aplicado. Porto Alegre: Artmed, 2004.

CASTRO, R. D. et al. b-Tubulin accumulation and DNA replication in imbibing tomato seeds. Plant Physiology, Rockville, v. 109, p. 499-504, 1995.

COSTA, P. R. et al. Estresse hídrico induzido por 
manitol em sementes de soja de diferentes tamanhos. Revista Brasileira de Sementes, Brasília, v. 26, n. 1, p.105-113, 2004.

CROMARTY, A. S.; ELLIS, R. H.; ROBERTS, E. $H$. Design of seed storage facilities for genetic conservation. Rome: International Board of Plant Genetic Resources, 1990. 109 p.

DAVIDE A. C.; FARIA, J. M. R.; BOTELHO, S. A. Propagação de espécies florestais. Belo Horizonte: CEMIG/UFLA/FAEPE, 1995. 40 p.

ELLA, E. S.; DIONISIO-SESE, M. L.; ISMAIL, A. M. Seed pre-treatment in rice reduces damage, enhances carbohydrate mobilization and improves emergence and seedling establishment under flooded conditions. AoB Plants, Oxford, v. 7, p. 1-11, 2011.

FERRAZ-GRANDE, F. G. A.; TAKAKI, M. Temperature dependent seed germination of Dalbergia nigra Allem (Leguminosae). Brazilian Archives of Biology and Technology, Curitiba, v. 44, p. 401-404, 2001.

FERREIRA, S. A. N.; GENTIL, D. F. O. Extração, embebição e germinação de sementes de tucumã (Astrocaryum aculeatum). Acta Amazônica, Manaus, v. 36, p. 141-146, 2006.

FUJIKURA, Y. et al. Hydropriming, a simple and inexpensive priming method. Seed Science and Technology, Bassersdorf, v. 21, p. 639-642, 1993. GALLARDO, K. et al. Proteomic analysis of Arabidopsis seed germination and priming. Plant Physiology, Rockville, v. 126, p. 835-848, 2001.

GASPAR, C. M.; NAKAGAWA, J. Influência do tamanho na germinação e no vigor de sementes de milheto (Pennisetum americanum (L.) Leeke). Revista Brasileira de Sementes, Londrina, v. 24, n. 1, p. 339-344, 2002.

GHASSEMI-GOLEZANI, $K$. et al. Effects of hydro-priming duration on seedling vigour and grain yield of pinto bean (Phaseolus vulgaris L.) cultivars. Notulae Botanicae HortiAgrobotanici, Cluj-Napoca, v. 38, n. 1, p. 109-113, 2010.

GUIMARÃES, M. A.; DIAS, D. C. F. S.; LOUREIRO, M. E. Hidratação de sementes. Revista Trópica, Chapadinha, v. 2, n. 1, p. 31-39, 2008.

IBAMA. Lista Oficial de Flora ameaçada de extinção. Disponível em: <http://www.ibama.gov. br/flora $>$. Acesso em: 2 maio 2010.

KHAZAEI, J.; MOHAMMADI, N. Effect of temperature on hydration kinetics of sesame seeds (Sesamum indicum L.). Journal of Food Engineering, Davis, v. 91, p. 542-552, 2009.
KISSMANN, C. et al. Germinação de sementes de Stryphnodendron mart osmocondicionadas. Revista Brasileira de Sementes, Londrina, v. 32, n. 2, p. 26-35, 2010

LABOURIAU, L. G. A germinação das sementes. Washington: Secretaria Geral da O.E.A., 1983. $173 \mathrm{p}$.

LARRÉ, C. F.; MORAES, D. M.; LOPES, N. F. Potencial fisiológico de dois lotes de sementes de arroz tratadas com 24-epibrassinolídeo. Revista Brasileira de Sementes, Brasília, v. 31, n. 4, p. 27 35, 2009.

LI, J. et al. Effects of light, hydropriming and abiotic stress on seed germination, and shoot and root growth of pyrethrum (Tanacetum cinerariifolium). Industrial Crops and Products, St Martin d'Heres, 2011 (no prelo).

LIMA, L. B.; MARCOSFILHO, J.Condicionamento fisiológico de sementes de pepino e germinação sob diferentes temperaturas. Revista Brasileira de Sementes, Brasília, v. 32, n. 1, p.138-147, 2010.

LORENZI, H. Árvores brasileiras: manual de identificação e cultivo de plantas arbóreas nativas do Brasil. Nova Odessa: Plantarum, 1992.

MAEDA, J. A. C. et al. Discriminação entre lotes de sementes de girassol através do teste de envelhecimento rápido. Bragantia, Campinas, v. 45, n. 1, p. 133-141, 1986.

MAGUIRE, J. D. Speed of germination: aid in selection and evaluating or seedling emergence and vigour. Crop Science, Madison, v. 2, n. 2, p. 176-177, 1962.

MARCOS FILHO, J. M. Fisiologia de sementes de plantas cultivadas. Piracicaba: FEALQ, 2005. 495 p.

MARQUES, M. A.; PAULA, R. C.; RODRIGUES, T. J. D. Adequação do teste de condutividade elétrica para determinar a qualidade fisiológica de sementes de jacarandá-da-bahia (Dalbergia nigra (VELL) Fr. All. Ex Benth.). Revista Brasileira de Sementes, Brasília, v. 24, n. 1, p.271-278, 2002a.

Diferenciação de lotes de sementes de jacarandá-da-bahia (Dalbergia nigra (VELL.) Fr. All. Ex Benth.) pelo teste de germinação em laboratório e viveiro. Revista Brasileira de Sementes, Brasília, v. 24, n. 1, p. 244-247, 2002 b. MARTINS, C. C.; PEREIRA, M. R. R.; MARCHI, S. R. Germinação de sementes de Melaleuca quinquenervia em condições de estresse hídrico e salino. Planta Daninha, Viçosa, v. 29, n. 1, p. 1-6, 2011.

MAUREL, C. et al. Plant aquaporins: membrane 
channels with multiple integrated functions. Annual Review of Plant Biology, Palo Alto, v. 59, p. 595-624, 2008.

MENDONÇA, A. V. R. et al. Efeito da hidratação e do condicionamento osmótico em sementes de pau-formiga. Revista Brasileira de Sementes, Brasília, v. 27, n. 2, p. 111-116, 2005.

MORADI, A.; YOUNESI, O. Effects of osmo and hydro-priming on seed parameters of grain sorghum. Australian Journal of Basic and Applied Sciences, Amman, v. 3, p.1696-1700, 2009.

MURUNGU, F. S. Effects of seed priming and water potential on seed germination and emergence of wheat (Triticum aestivum L.) varieties in laboratory assays and in the field. African Journal of Biotechnology, Bowie, v. 10, n. 21, p. 43654371, 2011.

OHTO, M. et al. Effects of APETALA2 on embryo, endosperm, and seed coat development determine seed size in Arabidopsis. Sexual Plant Reproduction, Wageningen, v. 22, p. 277-289, 2009.

OSBORNE, D. J. Function of DNA synthesis and DNA repair in the survival of embryos during early germination and in dormancy. Seed Science Research, Wageningen, v. 3, p. 43-53, 1993.

PAZDERA, J.; HOSNEDL, V. Effects of Hydration treatments on seed parameters of difference lettuce (Lactuca sativa L.) seed lots. HortScience, Virgínia, v. 1, p. 12-16, 2002.

PEREZ, S. C. G. A.; NEGREIROS, G. F. Précondicionamento na viabilidade e no vigor de sementes de canafístula (Peltophorum dubium (Spreng) Taub) em condições de estresse. Revista Brasileira de Sementes, Brasília, v. 23, n. 1, p. 175-183, 2001.

PINEDO, G. J. V.; FERRAZ, I. D. K. Hidrocondicionamento de Parkia pendula [Benth ex Walp]: sementes com dormência física de árvore da amazônia. Revista Árvore, Viçosa, v. 32, n. 1, p. 39-49, 2008.

POWELL, A. A. et al. The influence of aerated hydration seed treatment on seed longevity as assessed by the viability equations. Journal of Experimental Botany, Lancaster, v. 51, n. 353, p. 2031-2043, 2000.

RABOTEAUX, N. N. G.; ANDERSON, N. O. Germination of Cleome hassleriana and Polanisia dodecandra seed lots in response to light, temperature and stratification. Research Journal of Seed Science, Dubai, p. 1-17, 2009.
RAMOS, F. N. et al. Comparação entre métodos de secagem na determinação do grau de umidade em sementes de Parkia multijuga Benth. (Leguminosa Mimonoideae). Revista Árvore, Viçosa, v. 24, n. 2, p. 175-179, 2000.

RÊGO, G. M.; POSSAMAI, E. Jacarandá-daBahia (Dalbergia nigra Vellozo) LeguminoseaePapilionoidae: produção de mudas. Comunicado Técnico Embrapa, n. 106, p. 1-3, 2003.

REIS, A. M. M.; CUNHA, R. Efeito do congelamento sobre a viabilidade de sementes de Anadenanthera peregrina (L.) Speg. com diferentes conteúdos de umidade. Pesquisa Agropecuária Brasileira, Brasília, v. 32, n. 10, p. 1071-1079, 1997.

RIZZINI, C. T. Árvores e madeiras úteis do Brasil: manual de dendrologia brasileira. São Paulo: Editora da USP, 1972. 294 p.

RUDRAPAL, D.; NAKAMURA, S. The effect of hydration-dehydration pretreatments on eggplant and radish seed viability and vigour. Seed Science and Technology, Bassersdorf, v. 16, p. 123-130. 1988.

SANTOS, S. R. G.; PAULA, R. C. Teste de envelhecimento acelerado para avaliação do vigor de lotes de sementes de Sebastiania commersoniana (Baill.) Smith \& Downs (branquilho) - Euphorbiaceae. Revista do Instituto Florestal, São Paulo, v. 19, n. 1, p. 1-12, 2007.

SCHWEMBER, A. R.; BRADFORD, K. J. A genetic locus and gene expression patterns associated with the priming effect on lettuce seed germination at elevated temperatures. Plant Molecular Biology, Zurich, v. 73, p. 105-118, 2010.

SUN, Y. D. et al. Effect of priming techniques on seed germination characteristics of $\mathrm{C}$. maxima Duch. Key Engineering Materials, Pfaffikon, v. 36, p. 474-476, 2011.

SUNG, F. J. M.; CHANG, Y. H. Biochemical activities associated with priming of sweet corn seeds to improve vigor. Seed Science and Technology, Bassersdorf, v. 4, p. 301-311, 1993.

VARIER, A.; VARI, A. K.; DADLANI, M. The subcellular basis of seed priming. Current Science, Bangalore, v. 99, n. 4, p. 450-456, 2010.

VÁZQUEZ-RAMOS, J. M.; SÁNCHEZ, M. D. L. P. The cell cycle and seed germination. Seed Science Research, Wageningen, v. 13, p. 113-130, 2004.

WOODSTOCK, L. W. Seed imbibition: a critical period for successful germination. Journal of Seed Technology, Moline, v. 12, n. 1, p. 1-15, 1988. 